063

\title{
Development of a flexible porous pipe using rubber crumb and recycled polyethylene
}

\author{
N Dayaratna and S Liyanage \\ Department of Chemistry, University of Sri Jayewardenepura, Sri Lanka.
}

The main objective of this study is to develop a porous flexible rubber pipe utilizing the rubber crumb and recycled polyethylene for micro irrigation system to maintain under ground moisture content.

The research work was mainly based on the formula development and the process development. Initially number of formulations based on the plastic binder and vulcanized rubber powder (rubber crumb) and their blends were used. After selecting some useful formulas, process development was carried out based on the temperature settings of the extruder barrels and the mixing characteristics of the blends.

Flexible porous pipe products based on the developed formulas were tested on range of application requirements such as strength properties (tensile \& tear strengths), resistance properties (UV, ESCR, chemical resistances), water discharge rate through its wall, pressure existence, durability and density of the product. Results obtained were evaluated to select the most suitable compound composition for porous pipes that yields the best compromise of processability parameters and performance characteristics.

After careful examination of performance applications and quality aspects of the selected product, a process was developed for commercial implementation with a competitive price. As the final product contains fairly high percentage of recycled rubber (rubber crumb) it is going to be one of the major solution for growth of the amount of wasted tire in the environment. The product based on the developed compound composition is fully implemented in commercial scale and expected to introduce to local market and also in foreign market.

\section{4 \\ Shrimp waste management: Use of dried papaya milk in chitosan manufacture \\ P A J Yapa, A Silva and W T P S K Senarath \\ Department of Botany, University of Sri Jayewardenepura, Sri Lanka.}

Chitin is the second most abundant carbon biopolymer on earth, next to cellulose. It is the major constituent in the exo-skeleton of crustacean water animals such as shrimps, crabs etc. Shrimp waste is a major cause for environmental pollution in shrimp cultivating areas such as Puttalam. Current annual shrimp production in Sri Lanka is about $4000 \mathrm{MT}$ and the shrimp waste produced is about 1200 MT. This shrimp waste at present is discharged into environment or buried without any treatment, thereby causing serious environmental pollution problems.

Chitosan, which can be obtained from chitin by chemical treatment, is a polysaccharide of very high economic importance with a wide range of industrial applications. If Sri Lanka can convert its shrimp waste in to chitosan, it can be a major foreign exchange earner, in addition to solving the problem of environmental pollution caused by shrimp waste.

A method for the production of chitosan from shrimp waste using dried papaya milk (DPM) has been developed (Sri Lanka Patent No 13544, 2005). It involves the treatment of demineralised (with $4 \%$ $\mathrm{HCl}$ ) shrimp waste with DPM followed by deproteinization with $3 \% \mathrm{NaOH}$ and deacetylation with $50 \% \mathrm{NaOH}$. The use of DPM brings about a $25 \%$ reduction in the amount of $\mathrm{NaOH}$, which is known to cause environmental pollution problems. Typically, the degree of deacetylation (DD) of resulting chitosan was $66 \%$ comparable to DD of conventional methods. Moisture content $(11.2 \%)$ and ash content $(0.69 \%)$ of resulting chitosan were also comparable to those obtained by $100 \%$ chemical methods.

Proceedings of the International Forestry and Environment Symposium 2006 of the 